\title{
EARLY CAREER RESEARCHERS
}

Transgenerational effects

of famine: initiation of the offsprings' study of Leningrad Siege survivors KRISTINA TOLKUNOVA, LYUDMILA KOROSTOVTSEVA, OXANA ROTAR

Almazov National Medical Research Centre
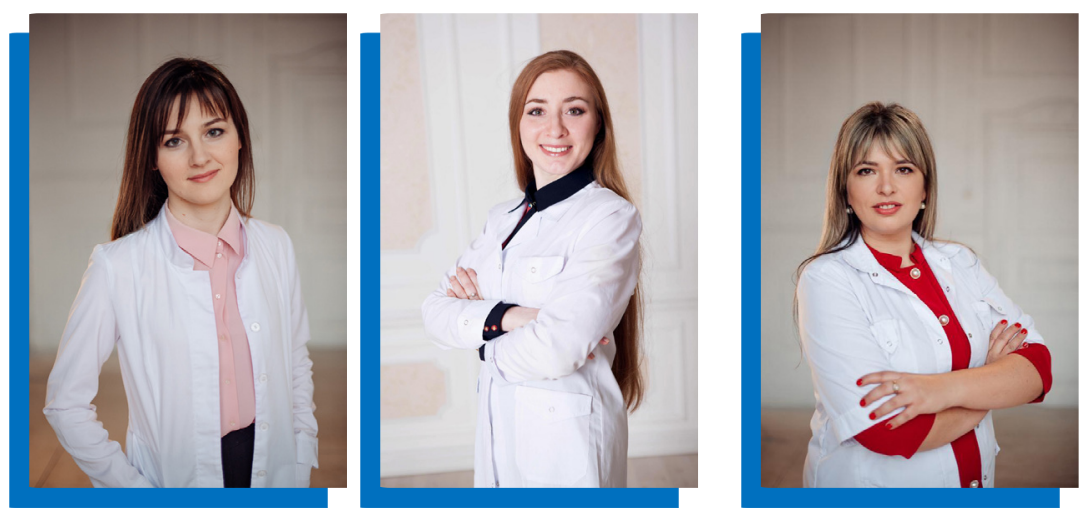

St Petersburg, Russia

DOI:10.30824/2112-13

A wide range of intrauterine influences can change the pathway of fetal development. Starving during pregnancy and early life stage is one of the most important reasons of remote cardiometabolic disorders in adulthood'. Such disorders develop due to plasticity when in a certain environment the most suitable phenotype is expressed ${ }^{2}$. The disease progression in adulthood may result from poor functional capacity of malfunctioning vital organs ${ }^{3}$.

The long-term nutritional effects during pregnancy can be assessed in human populations born during periods of natural disasters and wars. Given that the genetic composition of a population changes very slowly over many generations, DNA changes can hardly be evaluated to study the response to new environmental conditions4. On the contrary, epigenetics, defined as somatically inherited chemical modifications of DNA that do not entail changes in the sequence itself, is plastic and responsive to the environment. Since epigenetic layers respond to external and internal conditions by modulating their pattern of chemical modifications, they are sometimes called "mediators" between the environment and DNA ${ }^{4}$.

The study involving the inhabitants of besieged Leningrad, who suffered a long-term lack of nutrition during Second World War, and their offspring can contribute significantly to this field. The average daily diet for the majority of Leningrad residents during the siege was about 300 calories and contained almost no protein. The longitudinal study of 3905 Leningrad siege survivors carried out by Sparen in 2004 demonstrated that they were more likely to have higher blood pressure, as well as higher rates of mortality from coronary heart disease and stroke5. In 1997, the study by Stanner et al showed that intrauterine malnutrition and starvation in infancy of siege survivors were not associated with metabolic disorder or cardiovascular disease (CVD) in adulthood6.

The influence of environmental factors, and starvation in particular, can contribute to epigenetic transgenerational inheritance of phenotype variability ${ }^{7}$. It can increase susceptibility or tolerance to diseases development in next generations. Only few studies involved offspring of Leningrad Siege survivors. Professor Khoroshinina et al. (2017) found that prolonged starvation contributes to higher rates of obesity and death at younger age in Leningrad siege survivors ${ }^{8}$. Professor Rachkov examined the survivors and their descendants who often manifest musculoskeletal, cardiovascular, gastrointestinal and respiratory diseases ${ }^{9}$.

Our cohort study of 305 Leningrad siege survivors was carried out in 2009-2011. We found significantly lower anthropometric features and higher protective type of lipids (HDL) in survivors comparing with controls. The control group did not experience starvation and was comparable by sex and age. Telomere length has been suggested as a biomarker of aging and may be lifestyle related. Being the first study of $T / S$ telomere length in survivors it showed significantly shorter ratio comparing with controls ${ }^{10}$.

We are planning to examine the descendants of the Leningrad siege survivors comparing with sex- and age-matched controls. Our study aims at assessing the transgenerational effects of starvation at early stages of development on cardiometabolic disorders along with vascular ageing in 2 generations of survivors' offspring (children, grandchildren). The study is intended to estimate both early vascular ageing (EVA syndrome) and new phenotype SUPERNOVA ${ }^{11}$. SUPERNOVA patients 
demonstrate extremely low vascular stiffness for their age and gender independently of cardiovascular risk factors. The data on cardiometabolic and vascular transgenerational effects of starvation can be used to improve personalized cardiovascular prevention.

\section{REFERENCES}

1. Moguchaya EV, Rotar OP, Konradi AO. Intrauterine undernutrition and hypertension and cardiovascular risk. "Arterial'naya Gipertenziya" ("Arterial Hypertension"). 2013;19(4):299-304. In Russian doi. org/10.18705/1607-419X-2013-19-4-203-213

2. West-Eberhard MJ. Developmental plasticity and the origin of species differences. Proc Natl Acad Sci U S A. 2005;102:6543-9. doi: 10.1073/pnas.0501844102.

3. Hales CN, Barker DJ. The thrifty phenotype hypothesis. Br Med Bull. 2001;60:5-20. doi: 10.1093/ bmb/60.1.5.

4. Yona AH, Frumkin I, Pilpel Y. A relay race on the evolutionary adaptation spectrum. Cell. 2015;163(3):54959. doi: 10.1016/j.cell.2015.10.005.

5. Sparén P, Vågerö D, Shestov DB, Plavinskaja S, Parfenova N, Hoptiar V, Paturot D, Galanti MR. Long term mortality after severe starvation during the siege of Leningrad: prospective cohort study. BMJ. 2004;328(7430):11. doi: 10.1136/bmj.37942.603970.9A.

6. Stanner SA, Bulmer K, Andrès C, Lantseva OE, Borodina V, Poteen VV, Yudkin JS. Does malnutrition in utero determine diabetes and coronary heart disease in adulthood? Results from the Leningrad siege study, a cross sectional study. BMJ. 1997; 315 (7119): 1342-8. doi: 10.1136 / bmj.315.7119.1342.

7. Perera BPU, Faulk C, Svoboda LK, Goodrich JM, Dolinoy DC. The role of environmental exposures and the epigenome in health and disease. Environ Mol Mutagen. 2020;61(1):176-192. doi: 10.1002/em.22311

8. Khoroshinina LP, Shabrov AV, Buyniov LG. Starvation in childhood and obesity in senior age. Pediatrician (St. Petersburg). 2017; 8 (6): 56-61. In Russian. doi: 10.17816 / PED8656-61.

9. Tulsky IV, Bagrov GI. Blockade Rachkov's syndrome, The Siege of Leningrad, 1941-1944 - Human losses, Siege Syndrome. Neva Pearl (St. Petersburg). 2006. In Russian.

10. Rotar O, Moguchaia E, Boyarinova M, Kolesova E, Khromova N, Freylikhman O, Smolina N, Solntsev V, Kostareva A, Konradi A, Shlyakhto E. Seventy years after the siege of Leningrad: does early life famine still affect cardiovascular risk and aging? J Hypertens. 2015;33(9):1772-9; discussion 1779. doi: 10.1097/ HJH.0000000000000640.

11. Laurent S, Boutouyrie $P$, Cunha PG, Lacolley $P$, Nilsson PM. Concept of Extremes in Vascular Aging. Hypertension. 2019;74(2):218-228. doi: 10.1161/ HYPERTENSIONAHA.119.12655 